\title{
ANTESEDEN DAN KONSEKUEN PENGGUNAAN MEDIA SOSIAL BAGI UMKM: ANALISIS PERSPEKTIF ORGANISASI
}

\author{
Anissa Hakim Purwantini \\ Friztina Anisa \\ Universitas Muhammadiyah Magelang \\ anissa.hakim@ummgl.ac.id
}

\begin{abstract}
Utilization of social media technology for business interests has been widely done both in large companies and MSMEs (Micro, Small and Medium Enterprise). Utilization of social media for MSMEs is very important to face the competition in this globalization era. This study empirically examines the antecedents of social media usage and its impact on MSMEs performance based on the Technology-Organization-Environment framework and Resource Based View theory. The survey method by distributing questionnaires was conducted to MSMEs from various industries in Magelang. Analysis with SEM-Partial Least Square indicates that customer pressure and mobile environment are significant factors affecting the use of social media. Furthermore, the dimensions of the impact on internal operations, sales, marketing and customer service are significant and make the value of social media usage for MSMEs. Technological competence and competitive pressure does not affect the social media usage for MSMEs.
\end{abstract}

Keywords: social media, SMEs, organization perspective, TOE, RBV

\section{PENDAHULUAN}

UMKM merupakan sektor yang memiliki peran strategis dalam perekonomian Indonesia. Berdasarkan data Kementerian Koperasi dan UKM, kontribusi UMKM terhadap PDB meningkat dari 57,84\% menjadi $60,34 \%$. Sedangkan penyerapan tenaga kerja juga mengalami peningkatan selama kurun waktu lima tahun terakhir dari 96,99\% menjadi 97,22\% (Mutmainah, 2016). Di era globalisasi ini UMKM dituntut untuk mampu bersaing dalam menghadapi segala tantangan global. UMKM harus mampu membenahi startegi pemasaran guna meningkatkan penjualan dan membangun hubungan jangka panjang dengan pelanggan. Oleh karena itu, UMKM harus mampu menganalisis berbagai potensi alternatif media untuk dimanfaatkan sebagai media pemasaran.

UMKM perlu mempertimbangkan media pemasaran yang dapat menawarkan berbagai macam keuntungan dengan biaya yang terbatas. Temuan empiris Stelzner (2011) menunjukkan bahwa media sosial menjadi solusi dan memainkan peran penting dalam pemasaran dan bisnis bagi usaha kecil dengan dua atau lebih karyawan. Pemanfaatan media sosial juga dapat menciptakan peluang baru dan sebagai media komunikasi dengan pelanggan (Jantsch 2010). Utami\&Purnama (2012) menemukan bahwa media sosial facebook tidak hanya berperan menjadi media promosi, tetapi juga media komunikasi dengan calon konsumen. Keuntungan yang didapatkan dari media sosial yang paling utama adalah penghematan biaya. Semua 
biaya pemasaran dapat dieliminasi dengan menggunakan media sosial. Pemasaran melalui media sosial mempunyai nilai yaitu memberikan platform yang potensial untuk mengekspose UMKM kepada konsumen dan memlihara hubungan dengan pelanggan dengan cara efektif serta murah (Schaupp\&Belanger 2014).

Penting bagi UMKM untuk memahami dan dapat mengidentifikasi nilai atau dampak yang dihasilkan dari upaya pemanfaatan media sosial bagi perkembangan bisnisnya. Beberapa penelitian terdahulu telah mengkaji penggunaan media sosial oleh individu (Heinrich dan Lim 2011; Scott dan Orlikowski 2012;) dan UMKM berdasarkan perspektif individu (Ainin et al. 2015; Odoom et al. 2017; Purwantini dan Anisa, 2018). Akan tetapi, masih sedikit riset yang menganalisis penggunaan dan dampak media sosial bagi UMKM berdasarkan pada perspektif organisasi.

Sebagian besar riset terdahulu terkait penggunaan media sosial oleh UMKM di Indonesia menggunakan metode penelitian kualitatif yaitu deskriptif observasional (Utami \& Purnama 2012; Siswanto 2013; Priambada 2015; Purwidiantoro \& Hadi 2016). Sehingga belum dapat digeneralisasi mengenai anteseden dan konsekuen penggunaan media sosial bagi UMKM berdasarkan perspektif organisasi. Motivasi penelitian ini adalah menutup gap penelitian terdahulu dengan mereplikasi penelitian Schaupp\&Belanger (2014) yang dilakukan di konteks negara maju. Penelitian ini bertujuan untuk menguji generalisasi model riset Schaupp\&Belanger (2014) dengan menggunakan konteks UMKM di negara berkembang. Model riset Schaupp\&Belanger (2014) menginvestigasi anteseden penggunaan media sosial berdasarkan pada perspektif organisasi dengan mendasarkan pada kerangka Technology-OrganizationEnvirontment (TOE) dan determinan nilai media sosial bagi UMKM berdasarkan pada teori Resource Based View (RBV).

\section{KAJIAN PUSTAKA DAN PENGEMBANGAN HIPOTESIS \\ Teori-Teori Penggunaan Media Sosial}

Penelitian terdahulu mengenai media sosial mendasarkan pada teori yang menganalisa adopsi media sosial pada level individu meskipun mengkaji penggunaan media sosial pada level organisasi (Gangadharbatla 2008). Teori tersebut antara lain yaitu Theory of Planned Behaviour (TPB) dan Technology Acceptance Model (TAM). Namun demikian, beberapa peneliti berpendapat bahwa teori tersebut tidak tepat digunakan ketika mengkaji adopsi teknologi informasi pada level organisasi (Picoto et al. 2012). Teori yang tepat ketika mengkaji adopsi TI di level organisasi adalah Technology-Organization-Environment (TOE) (Srivastava dan Teo 2009; KuangWei dan Yan 2010; Picoto et al. 2012) dan teori Resource Based View (RBV) (Wade dan Hulldan 2004; Zhu dan Kraemer 2005). Kerangka TOE menyediakan sebuah dasar untuk mengidentifikasi potensial anteseden penggunaan media sosial, sedangkan RBV menghubungkan antara penggunaan media sosial dan nilainya (dampak penggunaan).

Pengembangan Hipotesis Penelitian

Anteseden Penggunaan Media Sosial

Faktor yang mempengaruhi penggunaan media sosial berdasarkan pada kerangka TOE (Tornatzky dan Fleischer 1990), terdapat tiga bagian utama yaitu: 1 . teknologi, 2. organisasi, 3. konteks lingkungan.

\section{Konteks Teknologi}

Fokus dari konteks teknologi dalam penelitian ini yaitu karakteristik dari teknologi media sosial yaitu social media tools. Ketika teknologi dapat memfasilitasi dan mendorong interaksi sosial, maka nilai itu dapat tercipta (Jantsch 2010). . Berdasarkan pada literatur sistem informasi, kompetensi teknologi terdiri dari infrastruktur teknologi dan sumber daya manusia yang mempunyai pengetahuan dan ketrampilan yang dibutuhkan dalam implementasi 
sebuah teknologi khusus (Zhu dan Kraemer 2005). Menurut Askool dan Nakata (2011) terdapat beberapa faktor yang dibutuhkan untuk mengadopsi media sosial antara lain infrastruktur teknologi, aplikasi, integrasi sistem, pelatihan karyawan. Kompetensi teknologi merepresentasikan infrastruktur teknologi dan pengetahuan serta ketrampilan karyawan yang dibutuhkan dalam penggunaan media sosial. Temuan empiris Schaupp\&Belanger (2014) menunjukkan bahwa terdapat pengaruh kompetensi teknologi terhadap penggunaan media sosial bagi UMKM.

$\mathrm{H} 1$ : Kompetensi teknologi berpengaruh positif terhadap penggunaan media sosial

\section{Konteks Organisasi}

Konteks organisasi dalam penelitian ini berfokus pada proses komunikasi dengan pelanggan. Secara lebih spesifik yaitu permintaan pelanggan kepada UMKM untuk menyediakan media sosial yang disebut dengan tekanan pelanggan. Menurut Teo et al (2003), pelanggan dapat melakukan tekanan kepada organisasi bisnis untuk mengimplementasikan sebuah inovasi berdasarkan pada tingkat bargaining power yang dimiliki pelanggan. Apabila pelanggan memiliki kekuatan yang cukup untuk meminta UMKM mengimplementasikan media sosial, kemungkinan besar UMKM akan memenuhi permintaan tersebut dengan menggunakan media sosial (Schaupp\&Belanger 2014). Hasil penelitian (Schaupp\&Belanger 2014) menemukan bukti pengaruh tekanan pelanggan terhadap penggunaan media sosial bagia UMKM.

$\mathrm{H} 2$ : Tekanan pelanggan berpengaruh positif terhadap penggunaan media social

\section{Konteks Lingkungan}

Konteks lingkungan dideskripsikan sebagai "tempat di mana sebuah perusahaan menyelenggarakan kegiatan bisnisnya yang mencakup industri, kompetitor, akses terhadap sumberdaya yang disediakan pemasok dan kesepakatan dengan pemerintah" (Tornatzky dan Fleischer 1990, 154). Dalam penelitian ini, lingkungan mencakup kompetisi (tekanan persaingan) dan sumberdaya (mobile environment) yang ada di UMKM. Pada konteks penggunaan media sosial, tidak terdapat peraturan pemerintah yang mengatur. Sehingga hanya tekanan persaingan dan sumberdaya yang dimasukkan ke dalam model penelitian.

Tekanan persaingan didefinisikan sebagai tingkat di mana sebuah organisasi dipengaruhi oleh kompetisi di dalam pasar. Penelitian terdahulu (Zhu dan Kraemer 2005) menyatakan bahwa kompetisi terhadap pesaing merupakan salah satu faktor penting dalam e-busniness, terlebih pada konteks media sosial terutama di lingkungan kompetitif (Askool dan Nakata 2011). Menurut Schaupp\&Belanger (2014), bisnis yang berada dalam lingkungan kompetitif akan lebih termotivasi untuk menggunakan advanced technologies, seperti media sosial.

H3: Tekanan persaingan berpengaruh positif terhadap penggunaan media sosial

Ketersediaan sumberdaya (mobile environment) di dalam UMKM berpengaruh terhadap adopsi dan penggunaan media sosial. Menurut Tarasewich et al. (2002), terdapat beberapa faktor yang memengaruhi penggunaan teknologi mobile diantaranya yaitu ketersediaan perangkat klien dan harga dari teknologi mobile seperti smartphone. Berdasarkan hasil survei Asosiasi Penyelenggara Jasa Internet Indonesia (APJII 2016) menunjukkan bahwa $47,6 \%$ dari 132,7 juta pengguna internet di Indonesia mengakses media sosial melalui perangkat mobile. Sebesar $97,4 \%$ menggunakan internet untuk mengakses media sosial. Operasi bisnis UMKM yang terdapat di lingkungan mobile akan lebih cenderung menggunakan media sosial. Schaupp dan Belanger (2014) menemukan bukti empiris bahwa mobile environment 
mendorong penggunaan media sosial bagi UMKM.

$\mathrm{H} 4$ : Mobile environment berpengaruh positif terhadap penggunaan media sosial

\section{Penggunaan Media Sosial dan Nilai Dampak}

Teori Resource Based View digunakan dalam penelitian ini sebagai penghubung antara penggunaan media sosial dan nilai dari penggunaannya bagi UMKM dalam penciptaan nilai pada berbagai dimensi. RBV ini berbeda dari pandangan strategi tradisional dimana lebih berfokus pada industri dan lingkungan, namun penekanan keunggulan kompetitif yang dimaksud adalah dalam konteks antara strategi dan sumber daya internal perusahaan (Mahoney dan Pandian 1992). Temuan penelitian (Schaupp \& Bélanger, 2014) menunjukkan bukti empiris nilai media sosial Facebook yang berdampak pada kinerja UMKM meliputi layanan kepada pelanggan, penjualan, pemasaran dan operasi internal. Berdasarkan uraian tersebut, maka H5aH5d penelitian ini adalah:

$$
\begin{array}{rlr}
\mathrm{H}_{5 \mathrm{a}}: & \begin{array}{l}
\text { Penggunaan media sosial } \\
\text { berpengaruh positif terhadap nilai } \\
\text { pada pelayanan pelanggan. }
\end{array} \\
\mathrm{H}_{5 \mathrm{~b}}: \begin{array}{l}
\text { Penggunaan media sosial } \\
\text { berpengaruh positif terhadap nilai } \\
\text { pada penjualan. }
\end{array} \\
\mathrm{H}_{5 \mathrm{c}}: \begin{array}{l}
\text { Penggunaan media sosial } \\
\text { berpengaruh positif terhadap nilai } \\
\text { pada pemasaran. }
\end{array} \\
\mathrm{H}_{5 \mathrm{~d}}: \begin{array}{l}
\text { Penggunaan media sosial } \\
\text { berpengaruh positif terhadap nilai } \\
\text { pada kinerja operasi internal. }
\end{array}
\end{array}
$$

\section{METODE PENELITIAN \\ Desain dan Sumber Data Penelitian}

Desain penelitian ini menggunakan metode survei yaitu metode pengumpulan data primer yang diperoleh secara langsung dari sumber asli melalui kuesioner. Unit analisis penelitian ini adalah organisasi, yaitu Usaha Mikro Kecil dan Menengah yang berada di wilayah Magelang. Fokus dari studi ini adalah analisis pengaruh anteseden dan konsekuen dari penggunaan media sosial bagi UMKM.

\section{Populasi dan Sampel Penelitian \\ Populasi dalam penelitian ini adalah UMKM yang telah menggunakan media sosial dalam pengelolaan bisnisnya. Teknik pengambilan sampel dilakukan dengan metode non-probability sampling yaitu convenience sampling, yaitu teknik penentuan sampel yang dilakukan dengan mengambil responden yang berkenan dijadikan sampel penelitian yang dalam usahanya telah menggunakan media sosial.}

\section{Definisi Operasional dan Pengukuran Variabel}

Penelitian ini menggunakan 9 variabel untuk menguji hipotesis. Instrumen yang digunakan di dalam penelitian ini beberapa diambil dari penelitian terdahulu yang juga telah digunakan oleh Schaupp dan Belanger (2014). Variabel laten yang diukur sebagai reflektif yaitu kompetensi teknologi, tekanan pelanggan, tekanan persaingan, mobile environment dan penggunaan media sosial. Sedangkan konsekuen dari penggunaan media sosial yaitu dimensi dampak terhadap operasi internal, pemasaran dan penjualan diukur sebagai model formatif sesuai dengan penelitian sebelumnya (Picoto et al. 2012). Dimensi dampak terhadap layanan pelanggan diukur menggunakan model reflektif karena item-item yang didapatkan berdasarkan wawancara merupakan ukuran yang interchangeable. Semua variabel diukur menggunakan skala Likert 5 poin dengan rincian sebagai berikut : (1) Sangat Tidak Setuju (STS); (2) Tidak Setuju (TS); (3) Netral (N); (4) Setuju (S); (5) Sangat Setuju (SS).

Kompetensi Teknologi dalam penelitian ini didefinisikan sebagai Kemampuan UMKM untuk memanfaatkan media sosial dan fasilitas media sosial yang ditawarkan 
dalam menunjang bisnis. Terdiri dari 3 item pernyataan yang diambil dari Picoto et al (2012); Zhu dan Kraemer (2005).

Tekanan Pelanggan didefinisikan sebagai permintaan pelanggan agar UMKM menyediakan layanan media sosial. Intsrumen terdiri dari 3 item pernyataan yang digunakan oleh Picoto et al (2012); Hsu et al (2006).

Tekanan Persaingan dalamp penelitian ini didefinisikan sebagai derajat organisasi (UMKM) dipengaruhi oleh kompetisi di dalam pasar. Intsrumen terdiri dari 2 item pernyataan yang diadopsi dari Picoto et al (2012); Zhu dan Kraemer (2005).

Mobile Environment didefinisikan sebagai derajat kegiatan organisasi (UMKM) dipengaruhi oleh adopsi dan penggunaan medsos. Terdiri dari 2 item pernyataan yang diambil dari Picoto et al (2012); Tarasewich et al (2002)

Penggunaan Media Sosial adalah faktor yang memengaruhi UMKM untuk menggunakan media sosial dan memberikan nilai pada organisasi. Instrumen terdiri dari 3 item pernyataan yang diadopsi dari Zhu dan Kraemer (2005); Zhu et al (2006).

Nilai pada Pelayanan Pelanggan merupakan persepsi manfaat yang dirasakan UMKM dalam penggunaan media sosial untuk meningkatkan kepuasan pelanggan. Terdiri atas 4 item pernyataan yang diadopsi dari Schaupp dan Belanger (2014).

Nilai pada Penjualan adalah Persepsi manfaat yang dirasakan UMKM dalam penggunaan media sosial terhadap penjualan. Terdiri atas 2 item pernyataan. Nilai pada Operasi Internal merupakan persepsi manfaat yang dirasakan UMKM dalam penggunaan media sosial terhadap aktivitas bisnis operasi internal UMKM. Instrumen terdiri dari 4 item pernyataan dan keduanya diadopsi dari Picoto et al (2012).

Nilai pada Pemasaran didefinisikan sebagai Persepsi manfaat yang dirasakan UMKM dalam penggunaan media sosial terhadap pemasaran. Terdiri dari 3 item pernyataan yang diadopsi dari Picoto et al
(2012); Schaupp dan Belanger (2014).

\section{Metode Analisis Data}

Model dalam penelitian ini diuji menggunakan SEM-PLS (Partial Least Square) dengan bantuan software SmartPLS 3.0. SEM-PLS dapat bekerja secara efektif dengan ukuran sampel kecil dengan model yang kompleks dan dapat digunakan untuk konstruk reflektif dan formatif (Abdillah dan Hartono 2015). Pengujian dalam PLS dilakukan pada model pengukuran (outer model) dan model struktural (inner model).

\section{Model Pengukuran}

Pengujian pada model pengukuran terdiri dari uji validitas dan reliabilitas. Uji validitas terdiri dari convergent validity dan discriminant validity. Convergent validity digunakan untuk menilai seberapa besar korelasi antara dua ukuran dari konsep yang sama. Pengukuran convergent validity pada konstruk reflektif dihitung dengan nilai loading factor dan Average Variance Extracted (AVE) yaitu jumlah kuadrat stdanardized factor dibagi dengan jumlah item pengukuran. Rule of thumb dari loading factor di atas 0.7 dan nilai AVE harus lebih tinggi dari 0.5 (Hair et al., 2014). Sedangkan pada konstruk formatif pengujian validitas menggunakan nilai weight dan Variance Inflation Factors (VIFs).

Dicriminant validity merupakan penilaian seberapa berbeda suatu konstruk dengan konstruk lainnya, yaitu diukur dengan membandingkan nilai AVE dari kedua konstruk dengan nilai kuadrat korelasi antara dua konstruk yang diuji tersebut. Rule of thumb discriminant validity yaitu nilai akar kuadrat AVE lebih besar daripada korelasi antar konstruk dan nilai cross-loadings rendah (Hair et al., 2014).

Uji reliabilitas digunakan untuk mengetahui konsistensi hasil dari pengukuran jika dilakukan pengukuran dua kali atau lebih terhadap gejala yang sama dengan alat ukur yang sama. Pengujian reliabilitas dilakukan dengan pengukuran yang memenuhi kriteria nilai composite 
reliability di atas 0,7 meskipun 0,6 masih dapat diterima (Hair et al., 2014). Semakin besar nilai cronbach's alpha maka semakin tinggi tingkat reliabilitas alat ukur yang digunakan.

\section{Model Struktural}

Inner model merupakan model struktural untuk memprediksi hubungan kausalitas antar variabel laten. Parameter yang digunakan untuk uji model adalah nilai $R$-Square $\left(R^{2}\right)$. Semakin tinggi nilai $R^{2}$, maka semakin baik model penelitian. Tingkat signifikansi dalam pengujian hipotesis ditunjukkan oleh nilai koefisien path (inner model). Rule of thumb skor koefisien yang ditunjukkan oleh nilai $t$-statistic harus di atas 1,64 untuk hipotesis one tailed pada pengujian hipotesis dengan menggunakan alpha 5\% (Hair et al., 2014).

\section{HASIL DAN PEMBAHASAN}

Total sampel yang terkumpul dalam penelitian ini adalah 75 UMKM dengan berbagai macam industri. Akan tetapi, terdapat 5 responden yang dikeluarkan karena tidak mengisi kuesioner secara lengkap. Akhirnya, total sampel dalam penelitian ini adalah 70 responden. Karakteristik responden dalam penelitian ini ditunjukkan pada Tabel 1. Responden sebagian besar didominasi perempuan, rentang usia antara $25-30$ tahun, pendidikan terakhir SMA/K dan bidang usaha pada industri kuliner.

\section{Model Pengukuran (Outer Model)}

Berdasarkan pengujian validitas dan reliabilitas konstruk reflektif (Tabel 2 terlampir), semua item telah memenuhi persyaratan loading factor semua item sudah di atas 0.7 dan nilai AVE lebih tinggi dari 0.5. Uji reliabilitas menunjukkan nilai $C R$ $>0,7$ pada semua konstruk dan cronbach's alpha $>0,7$ meskipun terdapat 4 konstruk bernilai cronbach's alpha di bawah 0,7 (tekanan pelanggan, tekanan persaingan, mobile environment, dan penggunaan media sosial) tetapi masih di atas 0,6 sehingga masih dapat diterima (Hair et al., 2014). Dengan demikian, dapat dinyatakan semua konstruk pada penelitian ini reliabel.

Pengujian validitas pada konstruk formatif pada Tabel 3 terlampir menunjukkan bahwa nilai weights pada semua konstruk signifikan, kecuali pada PSR3, OP2 dan OP3, hal ini mengindikasikan validitas terpenuhi. Indikator tersebut tetap dipertahankan dalam model dan tidak dikeluarkan mengingat setiap item merepresentasikan dimensi yang berbeda dari kepentingan konstruk formatif dan mempertahankan validitas konten (Chin 2010 dalam Schaupp\&Belanger 2014).

Pengujian multikolinearitas menggunakan nilai VIFs dan hasil pengujian menunjukkan bahwa semua item pada konstruk formatif memiliki nilai VIFs di bawah cutoff sebesar 3.3. Hal tersebut mengindikasikan tidak terjadi masalah multikolinearitas (Diamantopoulos dan Siguaw 2006).

\section{Model Struktural}

Hasil dari pengujian model struktural berdasarkan pada Gambar 1 menunjukkan bahwa niali $\mathrm{R}^{2}$ pada penggunaan media sosial sebesar $46,5 \%$. Sedangkan pada dimensi nilai media sosial, nilai $\mathrm{R}^{2}$ untuk dampak pada pelayanan pelanggan $27,5 \%$ , dampak pada penjualan sebesar $48,8 \%$, dampak pada pemasaran sebesar $44,7 \%$, dan dampak pada operasi internal sebesar $34,4 \%$.

Dari empat hipotesis yang diajukan sebagai anteseden penggunaan media sosial bagi UMKM, hanya dua hipotesis yang terdukung. Penggunaan media sosial dipengaruhi oleh terbangunnya mobile environment di lingkungan operasi bisnis UMKM $(0,325)$ dan besarnya tekanan pelanggan $(0,308)$. Hasil path analisis menunjukkan tingkat signifikansi di bawah 0,05 sehingga mendukung $\mathrm{H} 2$ dan $\mathrm{H} 4$. Kompetensi teknologi $(\mathrm{H} 1)$ dan tekanan persaingan $(\mathrm{H} 3)$ tidak berpengaruh signifikan terhadap penggunaan media sosial bagi 
UMKM dengan signifikansi masing-masing sebesar 0,175 dan 0,068 . Nilai path terbesar untuk model penggunaan media sosial dan dimensi nilai sebesar 0,695 untuk dampak pada penjualan, dampak pada pemasaran sebesar 0,665 , dampak pada operasi internal sebesar 0,580 dan terakhir pada pelayanan pelanggan sebesar 0,521 . Nilai path dari keempat dimensi tersebut signifikan pada $p<0,0001$, hal ini mengindikasikan bahwa $\mathrm{H} 5 \mathrm{a}, \mathrm{H} 5 \mathrm{~b}, \mathrm{H} 5 \mathrm{c}$, dan $\mathrm{H} 5 \mathrm{~d}$ penelitian ini diterima. Hasil ini membuktikan bahwa teori RBV merupakan kerangka yang cocok untuk mengkaji nilai dari teknologi informasi pada level organisasi.

\section{PEMBAHASAN}

\section{Kompetensi Teknologi terhadap Penggunaan Media Sosial}

Hipotesis 1 menyatakan bahwa kompetensi teknologi berpengaruh positif dan instagram semakin mudah untuk dipelajari oleh orang awam (user friendly). Sehingga tidak diperlukan karyawan yang memiliki pengetahuan secara khusus di bidang teknologi informasi untuk mengoperasikan media sosial. Teknologi yang diperlukan untuk menjalankan media sosial juga tidak membutuhkan perangkat tambahan khusus. Cukup dengan teknologi smartphone dan paket data atau wifi yang tersedia sudah dapat mengakses media sosial. Oleh karena itu, kompetensi teknologi tidak berpengaruh terhadap penggunaan media sosial bagi UMKM.

\section{Tekanan Pelanggan terhadap Penggunaan Media Sosial}

Berdasarkan pengujian yang dilakukan, penelitian ini menemukan bukti empiris pengaruh tekanan pelanggan terhadap penggunaan media sosial, hal ini berarti

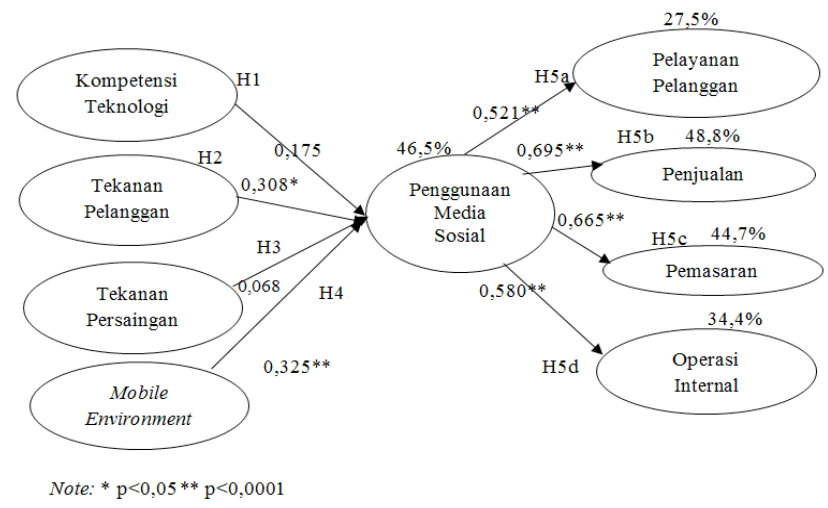

\section{Gambar 1.Pengujian Hipotesis}

terhadap penggunaan media sosial. Berdasarkan hasil pengujian ditemukan bahwa kompetensi teknologi tidak berpengaruh terhadap penggunaan media sosial bagi UMKM, sehingga $\mathrm{H} 1$ tidak terdukung. Jumlah ketersediaan teknologi yang dapat menyediakan penggunaan media sosial serta jumlah karyawan yang memiliki pengetahuan teknologi informasi untuk memfasilitasi penggunaan media sosial tidak memengaruhi penggunaan media sosial bagi UMKM.

Teknologi media sosial seperti facebook
$\mathrm{H} 2$ diterima. Semakin ketatnya persaingan dalam era global ini menjadikan pemilik bisnis UMKM berfokus pada pemeliharaan hubungan dengan pelanggan. Adanya permintaan konsumen untuk mengimplementasikan teknologi media sosial ke dalam kegiatan bisnis dapat menjadi pemicu UMKM menggunakan media sosial. Permintaan konsumen tersebut untuk memudahkan komunikasi dan pertukaran informasi. Terlebih permintaan yang datang dari pelanggan yang mempunyai posisi "bargaining power" tinggi. Sehingga 
Tabel 1. Karakteristik Responden

\begin{tabular}{|c|c|c|c|}
\hline \multicolumn{2}{|c|}{ Karakteristik Responden } & \multicolumn{2}{|c|}{ Jumlah } \\
\hline \multirow{2}{*}{$\begin{array}{l}\text { Jenis } \\
\text { Kelamin }\end{array}$} & Laki-laki & 32 & $45,7 \%$ \\
\hline & Perempuan & 38 & $54,3 \%$ \\
\hline \multirow{6}{*}{ Usia } & 21-24 tahun & 17 & $24,3 \%$ \\
\hline & 25-30 tahun & 22 & $31,4 \%$ \\
\hline & 31-35 tahun & 8 & $11,4 \%$ \\
\hline & 36-40 tahun & 4 & $5,7 \%$ \\
\hline & $41-50$ tahun & 15 & $21,4 \%$ \\
\hline & diatas 50 tahun & 4 & $5,7 \%$ \\
\hline \multirow{3}{*}{$\begin{array}{l}\text { Pendidi- } \\
\text { k a n } \\
\text { Terakhir }\end{array}$} & $\mathrm{SMA} / \mathrm{K}$ & 44 & $62,9 \%$ \\
\hline & Diploma (D3) & 4 & $5,7 \%$ \\
\hline & Sarjana (S1) & 22 & $31,4 \%$ \\
\hline \multirow{4}{*}{$\begin{array}{l}\text { Bidang } \\
\text { Usaha }\end{array}$} & Kuliner & 43 & $61,4 \%$ \\
\hline & Fotografi & 3 & $4,3 \%$ \\
\hline & Kerajinan & 12 & $17,1 \%$ \\
\hline & Merchandise & 12 & $17,1 \%$ \\
\hline
\end{tabular}

semakin besar tekanan dari pelanggan maka motivasi UMKM untuk menggunakan media sosial semakin meningkat. Hasil penelitian ini mendukung riset yang telah dilakukan Schaupp \& Belanger (2014).

\section{Tekanan Persaingan terhadap Penggunaan Media Sosial}

Penelitian ini tidak menemukan bukti bahwa tekanan persaingan berpengaruh positif terhadap penggunaan media sosial. Sehingga H3 penelitian ini tidak diterima. Pada konteks bisnis berskala kecil seperti UMKM, sebagian besar pelaku bisnis lebih berfokus pada konsumen, terutama pada potensial konsumen yang dapat dijadikan pelanggan. Selain itu, jarang UMKM yang memiliki banyak kompetitor secara langsung. Pelaku bisnis UMKM juga biasanya telah menciptakan kekhasan pada produknya yang membedakan dengan pesaingnya. Sehingga pesaing bukan menjadi fokus utama dalam menjalankan bisnisnya. Fokus utama mereka pada perluasan pangsa pasar dan bagaimana konsumen mereka dapat menjadi pelanggan yang loyal. Temuan empiris ini sejalan dengan hasil penelitian yang telah dilakukan Schaupp \& Belanger (2014).

\section{Mobile Environment terhadap Penggunaan Media Sosial}

Berdasarkan hasil pengujian didapatkan bahwa mobile environment berpengaruh positif terhadap penggunaan media sosial bagi UMKM. Hal ini menunjukkan bahwa $\mathrm{H} 4$ penelitian ini terdukung. Tersedianya berbagai macam produk smartphone di pasaran dengan berbagai fitur menarik disertai dengan harga yang semakin terjangkau mendorong UMKM dalam penggunaan media sosial. Setiap individu di jaman sekarang telah memiliki perangkat mobile pribadi seperti smartphone. Sehingga pelaku UMKM maupun konsumen memiliki sumberdaya yang memotivasi penggunaan media sosial untuk menunjang kegiatan bisnis. Hasil penelitian ini mendukung temuan empiris Schaupp \& Belanger (2014). 
Tabel 2. Pengujian Validitas dan Reliabilitas Konstruk Reflektif

\begin{tabular}{cccccc}
\hline & $\begin{array}{c}\text { Construct } \\
\text { Items }\end{array}$ & $\begin{array}{c}\text { Standardized } \\
\text { Loading }\end{array}$ & $\begin{array}{c}\text { Composite } \\
\text { Reliability }\end{array}$ & AVE & $\begin{array}{c}\text { Cronbach's } \\
\text { Alpha }\end{array}$ \\
\hline Kompetensi & KT1 & 0,742 & 0,829 & 0,619 & 0,717 \\
Teknologi & KT2 & 0,724 & & & \\
& KT3 & 0,884 & & & 0,663 \\
Tekanan & TP1 & 0,681 & 0,773 & 0,533 & \\
Pelanggan & TP2 & 0,747 & & & 0,641 \\
& TP3 & 0,758 & & & \\
Tekanan & TS1 & 0,955 & 0,827 & 0,710 & \\
Persaingan & TS2 & 0,712 & & & 0,614 \\
Mobile & ME1 & 0,877 & 0,837 & 0,713 & \\
environment & ME2 & 0,819 & & & \\
Penggunaan & PMS1 & 0,823 & 0,833 & 0,627 & \\
Media Sosial & PMS2 & 0,866 & & & 0,732 \\
& PMS3 & 0,674 & & & \\
Nilai pada & PP1 & 0,632 & 0,829 & 0,552 & \\
Pelayanan & PP2 & 0,657 & & & \\
Pelanggan & PP3 & 0,851 & & & \\
\hline
\end{tabular}

Tabel 3. Pengujian Validitas Konstruk Formatif

\begin{tabular}{ccccc}
\hline & $\begin{array}{c}\text { Construct } \\
\text { Items }\end{array}$ & $\begin{array}{c}\text { Standardized } \\
\text { Loading }\end{array}$ & Sig & VIF \\
\hline Nilai pada & PJL1 & 0,472 & 0,000 & 1,398 \\
Penjualan & PJL2 & 0,665 & 0,000 & 1,398 \\
& PSR1 & 0,747 & 0,000 & 1,368 \\
Nilai pada & PSR2 & 0,320 & 0,013 & 1,574 \\
Pemasaran & PSR3 & 0,128 & $0,141(\mathrm{~ns})$ & 1,211 \\
& OP1 & 0,759 & 0,000 & 1,171 \\
Nilai pada & OP2 & 0,211 & $0,222(\mathrm{~ns})$ & 2,364 \\
Operasi & OP3 & 0,243 & $0,173(\mathrm{~ns})$ & 2,605 \\
Internal & OP4 & 0,469 & 0,026 & 2,415 \\
\hline
\end{tabular}

\section{Penggunaan Media Sosial terhadap Nilai Media Sosial}

Berdasarkan hasil pengujian, semua dimensi nilai penggunaan media sosial bagi UMKM signifikan, artinya $\mathrm{H} 5 \mathrm{a}-\mathrm{H} 5 \mathrm{~d}$ terdukung. Penggunaan media sosial berdampak pada pelayanan pelanggan, penjualan, pemasaran dan operasi internal UMKM. Pengaruh terbesar penggunaan media sosial adalah dampak pada penjualan, yaitu tingkat penjualan produk meningkat dan meluasnya area penjualan. Hal ini 
merupakan nilai dari penggunaan media sosial sebagai media komunikasi dengan pelanggan dan juga promosi yang akhirnya meningkatkan penjualan. Media sosial juga berperan efektif dalam pemasaran dengan mengurangi biaya pemasaran, meningkatkan fleksibilitas promosi dan meningkatkan pengendalian atas tujuan pemasaran secara langsung. Selain itu penggunaan media sosial berpengaruh terhadap operasi internal UMKM. Diantaranya yaitu peningkatan produktivitas karyawan, kepuasan dan motivasi karyawan, serta efektivitas karyawan. Terakhir yaitu nilai dari penggunaan media sosial pada pelayanan pelanggan meliputi peningkatan layanan dan kepuasan pelanggan dan memfasilitasi komunikasi dengan pelanggan. Media sosial memudahkan dan melancarkan komunikasi antara pelaku bisnis dan konsumen. Melalui media sosial, konsumen dapat menyampaikan order, saran terhadap produk, dan bertukar informasi. Sehingga media sosial dapat meningkatkan layanan terhadap pelanggan. Hasil penelitian ini mendukung temuan empiris yang telah dilakukan oleh Utami dan Purnama (2012); Schaupp \& Belanger (2014); dan Priambada (2015).

\section{SIMPULAN}

Penelitian ini memberikan bukti empiris hubungan antara anteseden, penggunaan media sosial dan nilai yang didapatkan dari penggunaan media sosial tersebut bagi UMKM berdasarkan pada perspektif organisasi. Temuan penelitian ini secara garis besar dapat menggeneralisasi model penelitian Schaupp\&Belanger (2014) yang diterapkan dalam konteks negara berkembang.

Dua dari empat hipotesis anteseden penggunaan media sosial terbukti signifikan yaitu tekanan pelanggan dan mobile environment. Terbukti bahwa lingkungan yang menyediakan fasilitas mobile seperti smartphone dan wifi akan mendorong UMKM dalam penggunaan media sosial. Adanya tekanan pelanggan juga memotivasi dalam penggunaan media sosial untuk menunjang kegiatan bisnis UMKM. Di era globalisasi ini, customer relationship management sangat diperlukan untuk memelihara loyalitas pelanggan. Sehingga keuntungan UMKM dan keberlangsungan usaha dapat dipertahankan.

Kompetensi teknologi dan tekanan persaingan tidak berpengaruh terhadap penggunaan media sosial bagi UMKM. Hal tersebut mengindikasikan bahwa media sosial pada saat ini telah populer sehingga hampir semua kalangan dapat mengoperasikannya secara mudah tanpa kendala yang berarti. Pengguna tidak membutuhkan kompetensi teknologi yang kompleks untuk media sosial.

Keempat dimensi dari nilai penggunaan media sosial terbukti signifikan. Hal tersebut menunjukkan bahwa penggunaan media sosial memiliki dampak pada pelayanan pelanggan, penjualan, pemasaran dan operasi internal UMKM. Dampak terbesar penggunaan media sosial adalah nilai pada penjualan. Pemanfaatan media sosial dalam kegiatan bisnis akan meningkatkan penjualan produk dan memperluas pangsa pasar UMKM.

Saran untuk penelitian selanjutnya sebagai berikut : 1). Peneliti agar memperluas sampel penelitian pada wilayah dan jenis industri yang lebih beragam agar generalisasi hasil lebih baik. 2). Penelitian ini tidak menemukan bukti pengaruh tekanan persaingan dalam penggunaan media sosial. Penelitian selanjutnya dapat menginvestigasi kondisi yang dapat menciptakan tekanan persaingan menjadi faktor dalam penggunaan media sosial, seperti industri yang berskala besar. 


\section{DAFTAR PUSTAKA}

Abdillah, W., \& Hartono, J. 2015. Partial Least Square (PLS) Alternatif SEM dalam Penelitian Bisnis. Penerbit Andi. Yogyakarta.

Ainin, S., Parveen, F., Moghavvemi, S., Jaafar, N. I., \& Mohd Shuib, N. L. 2015. Factors influencing the use of social media by SMEs dan its performance outcomes. Industrial Management \& Data Systems, 115(3), 570-588. https://doi.org/10.1108/IMDS-07-2014$\underline{0205}$

APJII. 2016. Infografis Penetrasi dan Perilaku Pengguna Internet Indonesia, Survey 2016. Tersedia di: https://apiii.or.id/content/read/39/264/Survei-Internet-APJII-2016 (diakses pada 2 November 2017).

Askool, S., and K. Nakata. 2011. A conceptual model for acceptance of social CRM systems based on a scoping study. Al and Society 26 (3): 205.

Diamantopoulos, A., and J. A. Siguaw. 2006. Formative versus reflective indicators in organizational measure development: A comparison and empirical illustration. British Journal of Management 17 (4): 263-282.

Gangadharbatla, H. 2008. Facebook me: Collective self-esteem, need to belong, and internet self-efficacy as predictors of the iGeneration's attitudes toward social networking sites. Journal of Interactive Advertising 8 (2): 5-15.

Hair, J. F., W. C. Black, B. J. Babin, dan R. E. Danerson. 2014. Multivariate Data Analysis. 7th Edition. United States of America: Pearson Education Limited.

Heinrichs, J., J. Lim, dan K. Lim. 2011. Influence of social networking site and user access method on social media evaluation. Journal of Consumer Behaviour 10 (6): 347

Jantsch, J. 2010. Let's Talk: Social Media for Small Business. Vol. 2. Redmond, WA: Microsoft. Kuang-Wei, W., dan C. Yan. 2010. E-business value creation in small and medium enterprises: A U.S. Study using the TOE framework. International Journal of Electronic Business 8 (1): 80-100.

Mahoney, J. T. dan Pandian, J. R. 1992. The Resource-Based View Within the Conversation of Strategic Management. Strategic Management Journal 13 (5).

Mutmainah, Dinda Audriene. 2016, 21 November. "Kontribusi UMKM Terhadap PDB Tembus Lebih Dari 60 Persen". CNN Indonesia. Tersedia di https://www.cnnindonesia.com/ ekonomi/20161121122525-92-174080/kontribusi-umkm-terhadap-pdb-tembus-lebihdari-60-persen/ (diakses pada 12 Desember 2017).

Odoom, R., Anning-Dorson, T., \& Acheampong, G. 2017. Antecedents of social media usage and performance benefits in small- dan medium-sized enterprises (SMEs). Journal of Enterprise Information Management, 30(3), 383-399. https://doi.org/10.1108/JEIM-042016-0088

Picoto, W., F. Be'langer, dan A. Palma-dos-Reis. 2012. Leveraging on Mobile Business to Enhance Firm Performance: An Organizational Level Study. Paper presented at the European Conference of Information Systems, Barcelona, Spain, June 10-13.

Priambada, S. 2015. "Manfaat Penggunaan Media Sosial Pada Usaha Kecil Menengah (UKM)". Seminar Nasional Sistem Informasi Indonesia, 2-3 November.

Purwantini, A. H. dan Anisa, F. (2018). Analisis Pemanfaatan Social Commerce bagi UMKM: Anteseden dan Konsekuen. Kompartemen Jurnal IImiah Akuntansi, 16 (1), Maret.

Purwidiantoro, M. H., S.W, K. D. F., \& Hadi, W. (2016). Pengaruh Penggunaan Media Sosial terhadap Pengembangan Usaha Kecil Menengah (UKM). Jurnal EKA CIDA, 1(1), 30-39.

Schaupp, L. C., \& Bélanger, F. 2014. The Value of Social Media for Small Businesses. Journal of Information Systems, 28(1), 187-207. https://doi.org/10.2308/isys-50674 
Scott, S., dan W. Orlikowski. 2012. Reconfiguring relations of accountability: Materialization of social media in the travel sector. Accounting, Organizations and Society 37 (1): 26.

Siswanto, T. (2013). Optimalisasi Sosial Media Sebagai Media Pemasaran Usaha Kecil Menengah. Liquidity, 2(1), 80-86.

Srivastava, S. C., dan T. S. H. Teo. 2009. E-government, e-business, dan national economic performance. Communications of AIS 26: 267-286.

Stelzner, M. A. 2011. Social Media Marketing Industry Report: How Marketers Are Using Social Media to Grow Their Businesses. Tersedia di: http://www.socialmediaexaminer.com/ social-mediamarketing-industry-report-2011/.

Tarasewich, P., R. C. Nickerson, and M. Warkentin. 2002. Issues in mobile commerce. Communications of the Association for Information Systems 8: 41-64.

Teo, H. H., K. K. Wei, dan I. Benbasat. 2003. Predicting intention to adopt interorganizational linkages: An institutional perspective. MIS Quarterly 27 (1): 19-49.

Tornatzky, L. G., dan M. Fleischer. 1990. The Process of Technological Innovation. Lexington, MA:Lexington Books.

Utami, A. D., \& Purnama, B. E. (2012). Pemanfaatan jejaring sosial sebagai media bisnis online (studi kasus di Batik Solo 85). Seruni FTI UNSA, 1, 1-7.

Wade, M., dan J. Hulldan. 2004. The resource-based view and information systems research: Review, extension, dan suggestions for future research. MIS Quarterly 28 (1): 107-142.

Zhu, K., dan K. Kraemer. 2005. Post-adoption variations in usage and value of e-business by organizations: Cross-country evidence from the retail industry. Information Systems Research 16: 61-84.Lampiran 